\title{
ESTRATÉGIAS DE ENSINO REMOTO E A COMPARAÇÃO COM O ENSINO PRESENCIAL NA ÁREA DE ENGENHARIA DE TRANSPORTES
}

\author{
Bruno Cavalcante Mota - brunomota@ det.ufc.br \\ Programa de Pós-Graduação em Engenharia de Transportes \\ Bloco 703, Campus do Pici, Av. Humberto Monte, s/n \\ 60455-760 - Fortaleza - Ceará
}

Francisco Heber Lacerda de Oliveira - heber@ det.ufc.br Programa de Pós-Graduação em Engenharia de Transportes Bloco 703, Campus do Pici, Av. Humberto Monte, s/n 60455-760 - Fortaleza - Ceará

Suelly Helena de Araújo Barroso - suelly @ det.ufc.br Programa de Pós-Graduação em Engenharia de Transportes Bloco 703, Campus do Pici, Av. Humberto Monte, s/n 60455-760 - Fortaleza - Ceará

Resumo: Em decorrência da emergente pandemia do novo Coronavírus, Instituições de Ensino Superior do Brasil e do mundo precisaram se reinventar para continuar a missão educacional. Nesse sentido, a Universidade Federal do Ceará (UFC) desenvolveu o Plano Pedagógico de Emergência para, inicialmente, definir as bases de estudos de discentes e de trabalho docente para retomada das atividades. Inserida na grade curricular do curso de Engenharia Civil da UFC, a disciplina de Projeto e Construção da Superestrutura Viária (PCSV) foi retomada de forma remota para duas turmas em junho de 2020. Dessa forma, o objetivo deste artigo é abordar as estratégias de ensino remoto adotadas em PCSV, comparando os resultados da primeira metade da disciplina, desenvolvida em 2020, com os de anos anteriores (2017, 2018 e 2019), nos quais foram desenvolvidas apenas atividades presenciais. Os resultados mostram que, no geral, a média da primeira avaliação parcial melhorou com o ensino remoto quando comparada com as aplicações presenciais.

Palavras-chave: Aulas remotas. Aulas presenciais. Engenharia Civil.

\section{INTRODUÇÃO}

Como consequência da situação pandêmica instaurada pelo novo Coronavírus (Covid19), as Instituições de Ensino Superior (IES) do Brasil e do mundo precisaram se reinventar para continuarem a missão educacional. Com a instalação do vírus no país, foi exigida a implantação de procedimentos para o enfrentamento à transmissão do vírus, incluindo, dentre outras ações, a necessidade de isolamento social. No âmbito educacional, foi necessária a suspensão das atividades presenciais, acarretando no adiamento ou cancelamento do calendário universitário de algumas IES, enquanto outras permitiram a continuidade de atividade de modo remoto. 
Diante disso, a Universidade Federal do Ceará (UFC) desenvolveu o Plano Pedagógico de Emergência (PPE) para, inicialmente, definir as bases de estudos de discentes e de trabalho docente para retomada das atividades do semestre corrente (2020.1). Nele são abordados os três cenários vigentes na universidade: (i) turmas praticando atividades remotas, com alunos participando e outros não; (ii) turmas que interromperam as atividades remotas, devido à baixa adesão dos estudantes ou por serem teórico-práticas e (iii) turmas que não realizaram atividades remotas, em função de decisões de conselhos ou dos próprios professores e alunos, incluindo ainda as que seriam totalmente práticas, teórico-práticas ou teóricas com difícil adaptação ao formato digital (UFC, 2020a).

O PPE, por meio da Pró-Reitoria de Graduação (PROGRAD), "assegura suportes pedagógico e tecnológico e, ainda, a acessibilidade pedagógica, metodológica, bem como de infraestrutura física e de segurança sanitária para a realização das atividades didáticas" (UFC, 2020b, p.1). Para isso, foram fornecidas aos estudantes, servidores docentes e técnicoadministrativos diversas ações formativas, permitindo que a comunidade acadêmica possa voltar, gradativamente, à rotina de estudos (UFC, 2020c). Dessa forma, o PPE definiu a data de 20 de julho de 2020 como base para a retomada total, de forma remota, das atividades acadêmicas da UFC, permitindo algumas disciplinas a retomarem durante o processo de transição (entre junho e julho), sendo o dia 22 de outubro de 2020 como data de referência para o fim do semestre.

No tocante aos cursos de engenharia, o contexto do ensino remoto pode apresentar algumas vantagens, como a flexibilidade de horários, autonomia no planejamento de estudos, além da disponibilidade de conteúdo e material didático mais personalizados e ajustados pelo professor segundo a necessidade da turma. Contudo, também existem desvantagens, como a impossibilidade de realização de aulas práticas, a utilização inadequada de recursos tecnológicos, a ausência de infraestrutura para a realização e acompanhamento das aulas, incluindo ainda, a desmotivação por parte de alunos que não se adaptem ao modelo. Fleury et al. (2014) relatam que a transposição de um curso presencial para a modalidade a distância, não conseguiu mobilizar plenamente os alunos da forma esperada.

Inserida na grade curricular do curso de Engenharia Civil da UFC, a disciplina de Projeto e Construção da Superestrutura Viária (PCSV) enquadra-se no cenário (iii) mencionado anteriormente. Ela possui três turmas semestrais em 2020.1, das quais duas retomaram as atividades em junho de 2020. Dessa forma, o objetivo geral deste artigo é abordar as estratégias de ensino remoto adotadas na disciplina de PCSV em 2020, nas turmas 02 e 04 cadastradas no Sistema Integrado de Gestão de Atividades Acadêmicas (SIGAA) da UFC, comparando os resultados da primeira metade do curso com os obtidos em anos anteriores (2017, 2018 e 2019), nos quais foram desenvolvidas atividades presenciais.

\section{ABORDAGENS DO ENSINO REMOTO}

A inesperada e inédita interdição do espaço físico das universidades, centros universitários e faculdades ocasionou a adoção de soluções digitais para tentarem reproduzir o que acontece em uma sala de aula presencial, na intenção de diminuir os impactos negativos do confinamento gerado pelo novo Coronavírus (IGTI, 2020). Algumas Instituições de Ensino Superior adotaram formatos com atividades síncronas e assíncronas para substituir as aulas presenciais, bem como novas formas de organizar o tempo pedagógico, permitindo a alteração do plano de ensino das disciplinas para se adaptar ao meio não presencial.

O ensino remoto, recomendado durante a pandemia do novo Coronavírus, aproxima-se da Educação a Distância (EaD), visto a utilização das Tecnologias da Informação e Comunicação (TICs) na mediação do processo. Contudo, diferencia-se, principalmente, no aspecto 
temporal, em decorrência das aulas serem ministradas em tempo real, com a possibilidade de interação online com o professor. Enquanto isso, a educação a distância é atemporal e assíncrona, mediada por tutores em plataformas virtuais (DESAFIOS DA EDUCAÇÃO, 2020). Castro (2009), ressalta que a EaD representa uma separação espacial entre alunos e professores; sendo assim, o modo como vão se comunicar depende da tecnologia existente.

A proposta de ensino remoto precisa conter preceitos importantes que possibilitem mais tempo de estudo aos estudantes e flexibilização da carga-horária que, se considerada equivalente ao ensino presencial, torna-se incompatível com o cenário de educação a distância emergente. Dessa forma, são necessários incentivos às metodologias ativas, bem como a um planejamento que permita a participação integrada dos alunos (IGTI, 2020).

Os alunos, principalmente os nativos digitais, estão cada vez mais conectados e interessados em processos automatizados, o que pode representar uma das vantagens desse modelo emergencial de ensino. Tanto na educação presencial como no ensino a distância, as TICs auxiliam na potencialização do processo de construção do conhecimento. A escolha das ferramentas tecnológicas possui um grande peso nesse processo de transformação digital do ensino. Existem inúmeras soluções disponíveis, mas nem todas estão adequadas à realidade institucional (MINHA BIBLIOTECA, 2018).

Os recursos didáticos empregados na $\mathrm{EaD}$ possuem características estruturais específicas, com possibilidades de níveis de diálogos distintos, a depender da mídia utilizada, que interferem no nível da distância espacial. O ambiente virtual não difere da forma presencial nessa questão de comunicação, já que o diálogo e a participação dos alunos são propiciados pela abordagem pedagógica adotada pelo docente e suas respectivas estratégias e mediações pedagógicas (RAMOS, SANTOS E FARIAS, 2016). É válido ressaltar, no entanto, que por não se encontrarem "olho no olho" com o professor nas plataformas virtuais, os alunos tendem a participar menos, visto a não-intimidação direta da troca de olhares.

De acordo com Vilela, Vilela e Lima (2016), o Ambiente Virtual de Aprendizagem, que é uma plataforma online para ensino e aprendizagem, permite a utilização de diversas ferramentas de comunicação, como arquivos de vídeo, de áudio, notas de aula, textos complementares e, inclusive, a troca em tempo real de informações. Os autores (p. 46) ainda ressaltam que um aspecto favorável ao amplo uso desses recursos "é permitir que o estudante possa experimentar uma forma de aprendizagem ativa, na qual o foco deixa de ser o professor e torna-se o próprio aluno". Sendo assim, nessa modalidade de ensino, o papel do professor é decisivo, pois os desafios de aprendizagem de cada estudante só serão superados com a devida orientação e ferramentas adequadas para suprir a deficiência do ensino.

\section{ESTUDO DE CASO}

A disciplina de Projeto e Construção da Superestrutura Viária é um componente curricular obrigatório inserida no $7^{\circ}$ semestre do curso de Engenharia Civil da UFC e aborda conteúdos relativos ao processo de projeto, construção e gerência de pavimentos, destacando os seguintes conteúdos: conceituação de pavimentação; ensaios de laboratório aplicados à pavimentação; estudos geotécnicos; camadas granulares; imprimação betuminosa; agregados e ligantes asfálticos; estudos de revestimentos; dimensionamento de pavimentos e gerência de pavimentos. Sendo assim, ela é dividida em duas partes, na qual a primeira abrange os cinco primeiros conteúdos e a segunda parte os demais.

No semestre 2020.1 foram ofertadas três turmas, das quais duas foram estudadas neste artigo (turmas 02 e 04). Inicialmente, quando ainda estavam permitidas as aulas presenciais, foram abordados os tópicos de conceituação de pavimentos e ensaios de laboratório aplicados à pavimentação, voltando os demais a serem estudados com o retorno das aulas remotas. Foi 
acordado entre alunos e professores que a disciplina funcionaria, prioritariamente, de forma síncrona, com as aulas transmitidas ao vivo pelo Google Meet, no mesmo horário que ocorriam as presenciais, permitindo a sua gravação e sendo disponibilizadas de forma assíncrona em canal no YouTube, intitulado Infraestrutura de Transportes, criado para a inserção das aulas e de vídeos temáticos aos assuntos relativos à disciplina. Além disso, todo o material abordado na disciplina como livros gratuitos, slides, normas abertas, dentre outros, foram anexados no Sistema Integrado de Gestão de Atividades Acadêmicas (SIGAA) para acesso a qualquer instante por intermédio dos alunos, possibilitando uma ampla variedade de materiais de estudo assíncrono.

No decorrer da disciplina, ocorreram aulas extras de "tira-dúvidas" e resolução de exercícios, em horário alternativo, escolhido pelos alunos, também de forma síncrona, com transmissão ao vivo pelo Google Meet. Elas foram gravadas e postadas no canal do YouTube para os alunos que ficaram impossibilitados de acompanhar a disciplina, majoritariamente, de forma assíncrona. Foram propostos trabalhos em equipe e individuais relativos aos temas abordados nas aulas, para comporem a nota final da disciplina, fornecida pela Equação (1), em que a média final (MF) da disciplina é obtida pela média simples das avaliações parciais 1 e 2 (AP1 e AP2), acrescida de até 1,0 ponto, referente à média dos trabalhos (MT). Dessa forma, seria possível o aluno aumentar a média final da disciplina com a entrega dos trabalhos.

$$
M F=\frac{A P 1+A P 2}{2}+M T \times 0,1
$$

Com relação às avaliações parciais, essas foram elaboradas no Google Forms, realizadas no mesmo horário das aulas remotas, com questões objetivas e práticas, nas quais os alunos precisaram anexar os cálculos manuscritos via PDF para receber a pontuação total ou parcial da questão. Durante todo o período das provas, os professores e os assistentes de ensino permaneceram online na sala virtual da disciplina para sanar quaisquer dúvidas provenientes dos alunos quanto à realização das avaliações.

Diante do exposto, o método de pesquisa deste artigo baseou-se na avaliação quantitativa das ferramentas utilizadas durante o período remoto, abordando porcentagem de frequência, visualizações e comentários das aulas e conteúdos extras disponibilizadas no canal do YouTube. Também foi realizada a comparação das notas da avaliação parcial 1 (AP1) realizada no semestre 2020.1 e nos semestres 2017.1, 2018.1 e 2019.1, de forma presencial, para analisar o comportamento da média geral da turma, incluindo parâmetros de desvio padrão, primeiro e terceiro quartil e mediana.

\section{RESULTADOS E DISCUSSÕES}

Os resultados são apresentados em três seções: (i) apresentação da composição de alunos em cada turma por semestre; (ii) análise das ferramentas utilizadas durante as aulas remotas, divididas em síncronas e assíncronas e (iii) análise do comportamento da média geral das turmas na AP1. É válido ressaltar que as análises foram possíveis em função das turmas serem conduzidas pelos mesmos docentes em todos os anos analisados e a prova ter sido a mesma para ambas as turmas (02 e 04), em cada ano de aplicação. A única exceção foi a turma 03, ministrada por um dos professores, que realizou uma prova diferente por razões de horário. 


\subsection{Quantidade de alunos das turmas de PCSV}

Para esta análise foram consideradas, excepcionalmente, três turmas em 2017 com 129 alunos, duas turmas de 2018 com 81 alunos e duas turmas de 2019 com 60 alunos, no modo presencial e duas turmas de 2020 com 57 alunos, no modo remoto. Os Gráficos 1 a 4 mostram a porcentagem de alunos em cada turma, nos respectivos anos.

Gráfico 1 - Quantidade de alunos das turmas de 2017

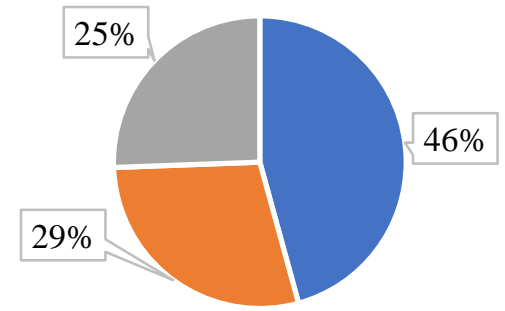

- TURMA $04 \quad$ - TURMA 02

- TURMA 03

Fonte: Os autores

Gráfico 3 - Quantidade de alunos das turmas de 2019

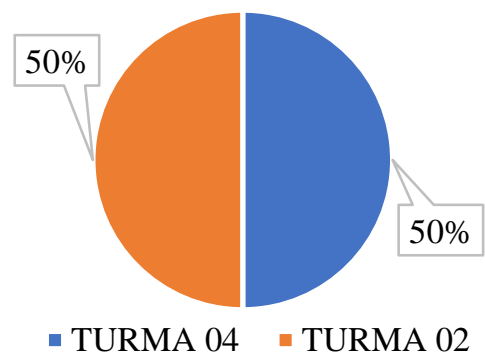

Fonte: Os autores
Gráfico 2 - Quantidade de alunos das turmas de 2018

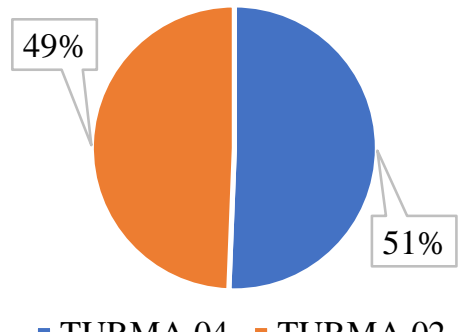

Fonte: Os autores

Gráfico 4 - Quantidade de alunos das turmas de 2020

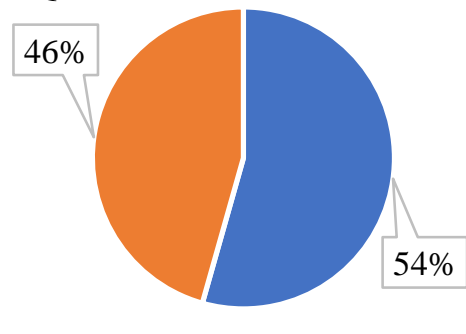

- TURMA 04 - TURMA 02

Fonte: Os autores

\subsection{Análise das ferramentas remotas utilizadas em 2020.1}

Nesta seção, os resultados são apresentados conforme o método proposto de ensino: com (i) atividades síncronas e (ii) assíncronas. Foram analisadas as participações nas aulas ao vivo pelo Google Meet e os índices quantitativos do canal da disciplina no YouTube.

\section{Participação nas aulas síncronas}

Para as aulas online em tempo real foi utilizada a plataforma do Google Meet, na qual foi criada uma sala virtual permanente até o final da disciplina, sendo o link disponibilizado para os alunos via e-mail, sistema acadêmico e grupo nas redes sociais, buscando atingir todos os alunos. Dessa forma, foram definidos 11 encontros para o fechamento das 48 horas/aula da disciplina, além da definição de 4 aulas extras de resolução de exercícios e discussão de resultados das respectivas avaliações parciais (AP1 e AP2). O Gráficos 5 apresenta a frequência dos alunos até a aula de realização da AP1, período de análise deste artigo.

Percebe-se, pelo Gráfico 5, que o encontro com mais participantes foi o de número 5, justamente o que correspondia ao dia de aplicação da AP1, com $85 \%$ de participação da Turma 02 e $90 \%$ de participação da Turma 04. Também é possível observar que para a Turma 02 , os encontros com menor porcentagem de frequência foram o primeiro e o quarto, com $62 \%$ de participação cada, enquanto que para a Turma 04, o encontro com menor porcentagem de frequência foi o primeiro, com $61 \%$ dos participantes. 


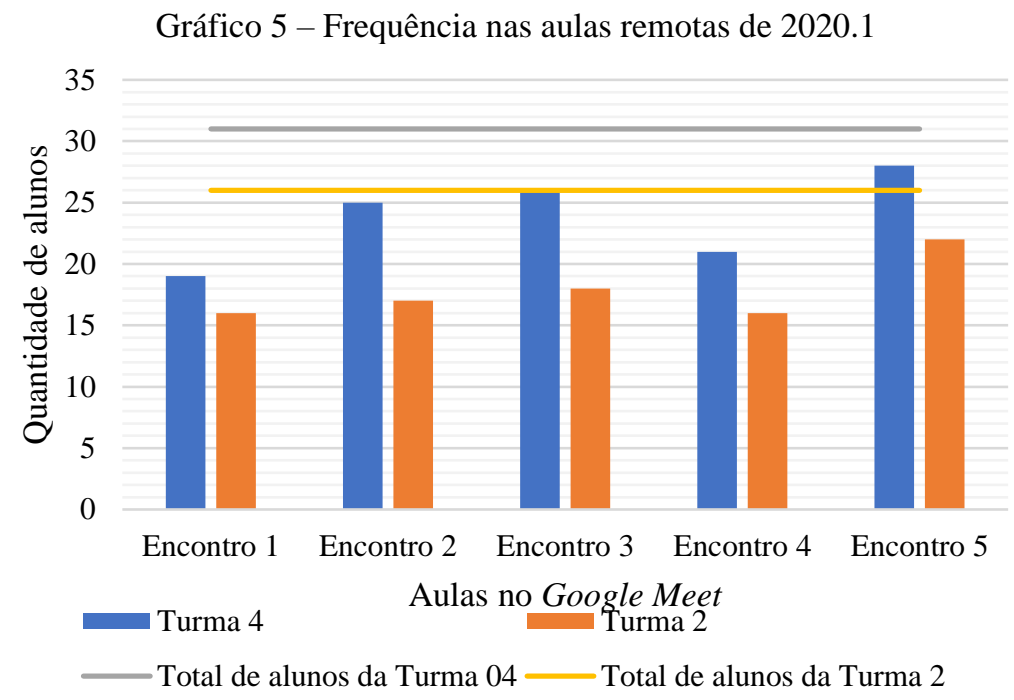

Fonte: Os autores

Ainda no tocante às atividades síncronas, foram realizadas duas aulas extras, uma para resolução de exercícios, anterior a AP1 e outra posterior a ela, para discussão dos seus resultados e resolução. Ambas foram realizadas em uma quinta-feira, à noite, no horário alternativo das $19 \mathrm{~h}$ às $20 \mathrm{~h}$, enquanto que as aulas normais eram realizadas na quarta-feira, pela manhã, no horário das $08 \mathrm{~h}$ às $10 \mathrm{~h}$. Participaram 54\% dos alunos na primeira aula extra e $42 \%$ na segunda aula, considerando a junção das duas turmas (57 alunos).

\section{Participação nas atividades assíncronas}

$\mathrm{Na}$ Tabela 1 estão apresentadas a quantidade de visualizações, de likes e de comentários dos encontros 2, 3 e 4, bem como dos vídeos temáticos desenvolvidos para auxílio aos estudos da AP1. O primeiro não foi disponibilizado no canal por se tratar apenas da reunião para definição de como seguiria a disciplina e o quinto não foi gravado, por corresponder à aplicação da AP1. Nas Figuras 1 e 2 estão telas correspondentes às playlists das aulas remotas e dos conteúdos temáticos, respectivamente.

Tabela 1 - Quantidade de acessos dos conteúdos disponibilizados no YouTube

\section{Tema do Vídeo} Visualizações Likes Comentários

\begin{tabular}{lccc}
\hline Encontro 2: Estudos Geotécnicos (17/06/2020) & 309 & 16 & 2 \\
\hline Encontro 3: Camadas Granulares (24/06/2020) & 157 & 12 & 1 \\
\hline Encontro 4: Camadas Granulares (01/07/2020) & 124 & 10 & 1 \\
\hline Vídeo temático 1: Conceituação de Pavimentos & 117 & 11 & 0 \\
\hline Vídeo temático 2: Estudos Geotécnicos & 82 & 11 & 0 \\
\hline Vídeo temático 3: Método de Rothfuchs & 203 & 9 & 0 \\
\hline Vídeo temático 4: Imprimação Betuminosa & 83 & 7 & 0 \\
\hline Aula extra 1: Resolução de exercícios (02/07/2020) & 128 & 13 & 0 \\
\hline Vula
\end{tabular}

Fonte: Os autores

Percebe-se, inclusive, que o vídeo temático do Método de Rothfuchs, elaborado para complementar a aula de Camadas Granulares, obteve expressivas 203 visualizações, chegando a ser o segundo vídeo mais assistido do canal. Isso aconteceu devido ao fato dele auxiliar os alunos na elaboração de um trabalho proposto na disciplina. 
(C) COBENCE

"Os desafios para formar hoje o engenheiro do amanhã"
$\mathrm{Ol} \mathrm{a} \mathrm{O3}$ de dezembro Evento On-line
Figura 1 - Tela da playlist de aulas remotas

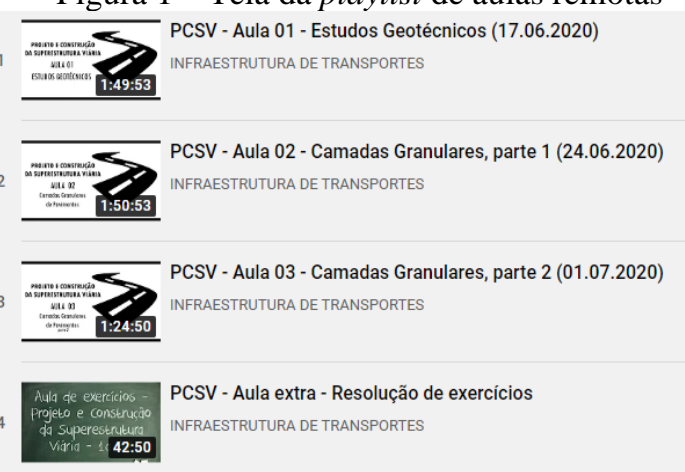

Fonte: Os autores
Figura 2 - Tela da playlist de vídeos temáticos

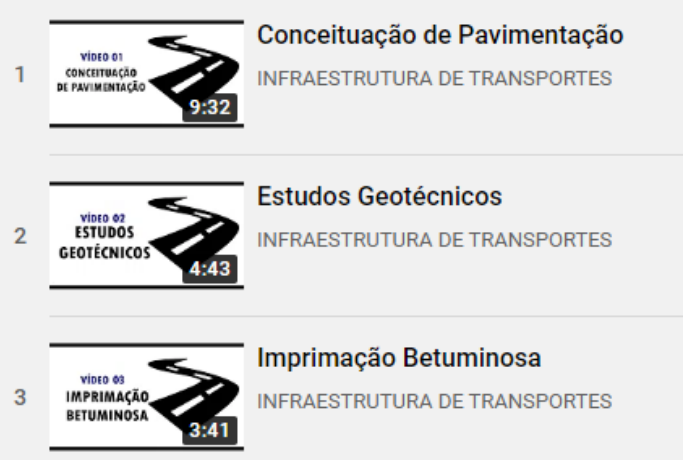

Fonte: Os autores

Pela Tabela 1 e pelas Figuras 1 e 2 percebe-se que, mesmo que todos os alunos não estejam acompanhando as aulas de forma síncrona, existe a possibilidade de que todos estejam assistindo aos conteúdos disponibilizados no canal. Ressalta-se ainda, a iniciativa como ação extensionista, visto que alcança um elevado número de pessoas. Ainda, é interessante ressaltar que, existem 192 inscritos no canal, no final do mês de julho de 2020, uma marca expressiva, considerada a quantidade de alunos da disciplina.

\subsection{Comparação das notas da AP1}

Nesta seção foram comparadas as médias gerais da AP1 das turmas de PCSV entre os anos de 2017 a 2019 com a do ano de 2020. Conforme comentado anteriormente, a prova foi realizada no Google Forms, com duração de 2 horas. Nas aplicações presenciais a duração era de, aproximadamente, 2,5 horas. Todas as provas tinham questões teóricas e práticas. No Gráfico 6 é apresentada a comparação de médias para a Turma 02 e para a Turma 04, respectivamente. Também é apresentada a média da Turma 03, analisada apenas para o ano de 2017.

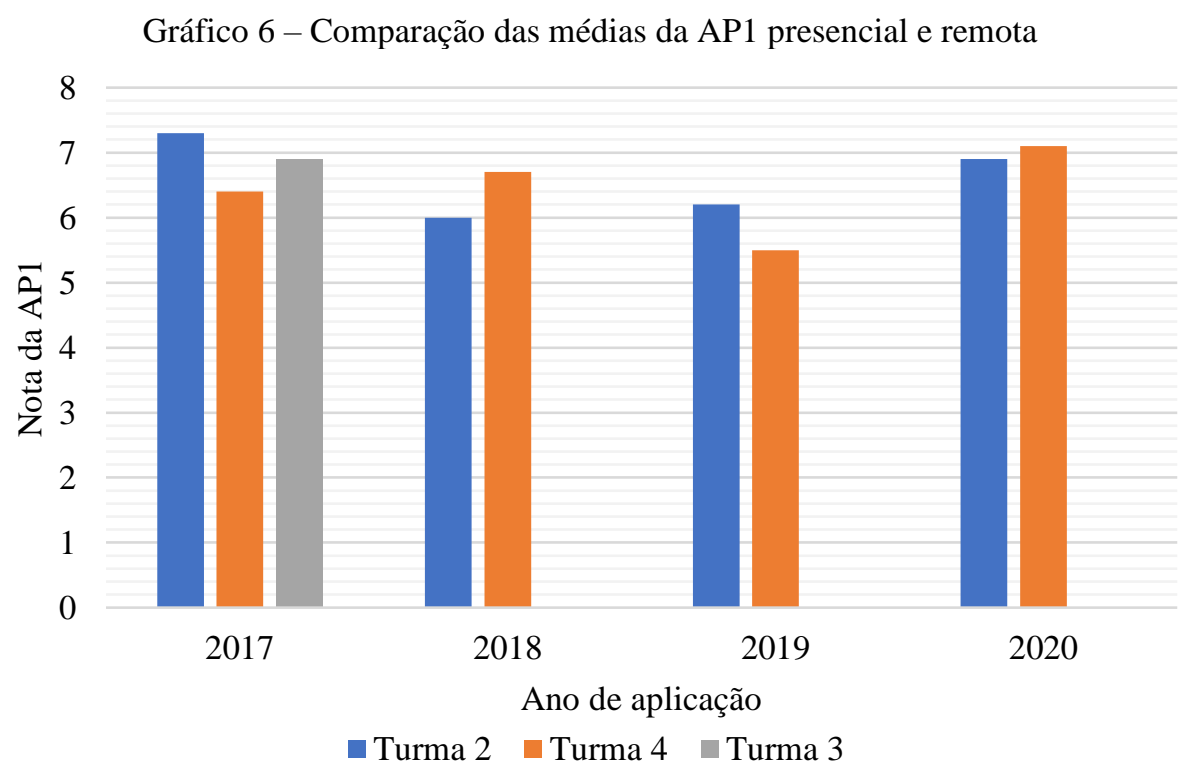

Fonte: Os autores 
Ainda, na Tabela 2, foram apresentados o primeiro e o terceiro quartil de cada turma, a mediana, a média e a diferença percentual com relação à AP1 de 2020. Também foi calculado o desvio padrão geral para cada aplicação, considerando a quantidade de alunos de cada turma e para as médias das AP1, considerando todas as aplicações. Esse último, resultando em um valor de 0,52 para a Turma 02 e de 0,56 para a Turma 04, mostrando a homogeneidade da média da primeira avaliação parcial, podendo permitir a constatação de que ela segue um padrão entre as aplicações analisadas.

Tabela 2 - Parâmetros estatísticos da AP1 para as Turmas 02 e 04

\begin{tabular}{c|cccc|cccc|c}
\hline Parâmetros & \multicolumn{6}{|c|}{ Turma 02 } & \multicolumn{5}{c|}{ Turma 04 } & T03 \\
estatísticos & $\mathbf{2 0 1 7}$ & $\mathbf{2 0 1 8}$ & $\mathbf{2 0 1 9}$ & $\mathbf{2 0 2 0}$ & $\mathbf{2 0 1 7}$ & $\mathbf{2 0 1 8}$ & $\mathbf{2 0 1 9}$ & $\mathbf{2 0 2 0}$ & $\mathbf{2 0 1 7}$ \\
\hline Média & 7,3 & 6,0 & 6,2 & 6,9 & 6,4 & 6,7 & 5,5 & 7,1 & 6,9 \\
Diferença (\%) & 5,8 & $-13,0$ & $-10,1$ & 0,0 & $-9,9$ & $-5,6$ & $-22,5$ & 0,0 & $-2,8$ \\
1 $^{\mathbf{0}}$ quartil & 7,0 & 4,8 & 5,4 & 5,8 & 5,6 & 5,9 & 4,1 & 5,9 & 5,8 \\
Diferença (\%) & 20,7 & $-17,2$ & $-6,9$ & 0,0 & $-5,4$ & 0,0 & $-30,5$ & 0,0 & $-1,7$ \\
3 $^{\text {o quartil }}$ & 8,8 & 7,1 & 7,3 & 8,2 & 7,8 & 7,5 & 6,7 & 8,8 & 8,7 \\
Diferença (\%) & 7,3 & $-13,4$ & $-11,0$ & 0,0 & $-11,4$ & $-14,8$ & $-23,9$ & 0,0 & $-1,1$ \\
Mediana & 8,1 & 6,1 & 6,5 & 7,0 & 6,8 & 6,5 & 5,1 & 7,1 & 7,7 \\
Diferença (\%) & 15,7 & $-12,9$ & $-7,1$ & 0,0 & $-4,2$ & $-8,4$ & $-28,2$ & 0,0 & 8,4 \\
Desvio Padrão & 2,3 & 1,7 & 1,4 & 1,6 & 1,8 & 1,2 & 2,0 & 1,7 & 2,6 \\
Diferença (\%) & 43,7 & 6,2 & $-12,5$ & 0,0 & 5,9 & $-29,4$ & 17,6 & 0,0 & 52,9 \\
Variância & 5,2 & 3,0 & 2,0 & 2,7 & 3,4 & 1,4 & 3,8 & 2,8 & 6,6 \\
Diferença (\%) & 92,6 & 11,1 & $-25,9$ & 0,0 & 21,4 & $-50,0$ & 35,7 & 0,0 & 135,7 \\
\hline
\end{tabular}

Fonte: Os autores

Percebe-se que para a Turma 02, a aplicação da prova de forma remota melhorou os índices, chegando a apresentar um crescimento de $13,4 \%$ do terceiro quartil quando comparado à aplicação de 2018, valor que representa que $75 \%$ dos alunos estão abaixo daquela nota e um aumento de $17,2 \%$ quando considerada a nota que representa que $25 \%$ dos alunos da turma estão abaixo dela. Percebe-se também que o desvio padrão da aplicação virtual foi o segundo menor. Contudo, observa-se que os melhores resultados, excluindo o desvio padrão e a variância, estão representados na aplicação de 2017.

Para a Turma 04 observou-se que a aplicação remota apresentou os melhores resultados, excluindo-se a mediana e o desvio padrão. Contudo, ficando esses parâmetros em segundo lugar. Mostrou-se ainda um aumento de 30,5\% da nota que representa que $25 \%$ dos alunos estão abaixo dela e um aumento de $23,9 \%$ na que representa que $75 \%$ dos alunos estão abaixo dela, quando comparadas com a aplicação de 2019.

Analisando as médias e medianas, percebe-se que para a maioria dos casos, com exceção dos anos de 2018, 2019 e 2020 da turma 04, a mediana é superior à média. Além disso, as maiores diferenças com relação à turma de 2020 são observadas na mediana, chegando a apresentar 28,2\% para a turma 04, no ano de 2019.

No que diz respeito à variância, notou-se que os maiores valores foram encontrados para a turma 02, no ano de 2017 e a turma 03, identificada como 2017b, ambas com elevada quantidade de alunos. Essas mesmas turmas foram as que se apresentaram mais distintas quando comparadas a aplicação de 2020. Inclusive, a variância demonstra que para a aplicação remota, não se apresentaram valores tão distantes da média. 


\section{CONSIDERAÇÕES FINAIS}

O trabalho abordou as ferramentas utilizadas na disciplina de Projeto e Construção da Superestrutura Viária no semestre 2020.1, quando foi necessária a realização de aulas remotas devido à pandemia do novo Coronavírus. Foi percebido que os alunos se engajaram, medianamente, tanto nas ações síncronas quanto nas assíncronas. Um canal no YouTube foi criado, permitindo a introdução de vídeos temáticos que resumiam ou complementavam as aulas virtuais e, ainda, a extensão do conteúdo para públicos diversos. Percebe-se que o vídeo elaborado do Método de Rothfuchs, assunto não ministrado na aula remota síncrona, foi o segundo vídeo mais assistido do canal em função da necessidade de os alunos aprenderem esse conteúdo para elaborarem um trabalho que valeria nota

No tocante às notas, foi percebido que a flexibilidade da realização da prova remota, pelo Google Forms, elevou à média e outros parâmetros estatísticos, no geral, quando comparada às aplicações presenciais. É válido ressaltar que a aplicação da prova ocorreu no horário da aula remota, como igualmente ocorreria no modelo presencial. Ainda, foi elaborada uma prova que seguisse o mesmo estilo das aplicadas anteriormente, envolvendo questões teóricas e práticas.

É importante destacar que se reconhecem as limitações apresentadas pelo método remoto de ensino, tanto para alunos quanto para professores, no tocante ao acesso por meio da internet, dispositivos disponíveis para o acompanhamento das aulas remotas e ambiente propício para aprendizagem. Contudo, observa-se que o método foi satisfatório para a primeira parte da disciplina, podendo ser replicado para outras disciplinas e, futuramente, para utilização em um sistema híbrido de ensino.

\section{Agradecimentos}

Os autores agradecem ao Conselho Nacional de Desenvolvimento Científico e Tecnológico $(\mathrm{CNPq})$ pela concessão de bolsa de mestrado para o primeiro autor.

\section{REFERÊNCIAS}

CASTRO, Cláudio de Moura. Embromação a distância?. 2009. Disponível em: http://www.regesd.tche.br/atualidades/claudio_moura_castro.htm. Acesso em: 25 jul. 2020.

DESAFIOS DA EDUCAÇÃO. Lições do coronavírus: ensino remoto emergencial não é EAD. 2020. Disponível em: https://desafiosdaeducacao.grupoa.com.br/coronavirus-ensinoremoto. Acesso em: 26 jul. 2020.

FLEURY, A. L. et al. Uma experiência de ensino de estatística a distância para um curso de engenharia. Revista de Ensino de Engenharia, v. 33, n. 1, p. 37-47, 2014.

IGTI. Educação pós-pandemia e a urgência da transformação digital. 2020. Disponível em: https://www.igti.com.br/blog/urgencia-da-transformacao-digital-na-educacao. Acesso em: 25 jul. 2020.

MINHA BIBLIOTECA. TICs na educação: desafios das tecnologias de informação e comunicação. 2018. Disponível em: https://minhabiblioteca.com.br/tics-na-educacao. Acesso em: 26 jul. 2020. 
RAMOS, Maria Claudice Teles; SANTOS, Silvania Nunes dos; FARIAS, Sônia Rodrigues. Educação a distância no ensino superior: as vantagens e desvantagens de um atual processo de ensino e aprendizagem. Trabalho de Conclusão de Curso. Faculdade São Luis de França. 2016. Disponível em: https://portal.fslf.edu.br/wp-content/uploads/2016/12/tcc9-1.pdf. Acesso em: 25 jul. 2020.

UFC. Plano Pedagógico de Emergência. 2020a. Disponível em: http://www.ufc.br/images/_files/noticias/200713_ppe.pdf. Acesso em: 18 jul. 2020.

UFC. Saiba como será a conclusão do semestre 2020.1 na UFC. 2020b. Disponível em: http://www.ufc.br/noticias/14815-saiba-como-sera-a-conclusao-do-semestre-2020-1-na-ufc. Acesso em: 25 jul. 2020.

UFC. Reposição de aulas: UFC oferece plano de formação com 19 cursos, oficinas e lives sobre novas tecnologias educacionais. 2020c. Disponível em:

http://www.ufc.br/noticias/14661-reposicao-de-aulas-ufc-oferece-plano-de-formacao-com-19cursos-oficinas-e-lives-sobre-novas-tecnologias-educacionais. Acesso em: 25 jul. 2020.

VILELA, André Luis da Mota; VILELA, Gilvânia Lúcia da Silva.; LIMA, Emerson de Oliveira. Ensino a Distância para Cursos Presenciais de Engenharia: o caso da Escola Politécnica de Pernambuco. Revista de Ensino de Engenharia, v. 35, n. 1, p. 44-56, 30 jun. 2016. http://dx.doi.org/10.15552/2236-0158/abenge.v35n1p44-56.

\title{
REMOTE TEACHING STRATEGIES AND COMPARISON WITH FACE-TO-FACE TEACHING IN THE AREA OF TRANSPORT ENGINEERING
}

\begin{abstract}
As a result of the emerging pandemic of the new Coronavirus, higher education institutions in Brazil and around the world needed to reinvent themselves to continue their educational mission. In this sense, the Federal University of Ceara (UFC) developed the Emergency Pedagogical Plan to initially define the bases for students' studies and teaching work to resume activities. As part of the curriculum of the UFC's Civil Engineering course, the subject of Design and Construction of the Road Superstructure (PCSV) was remotely resumed for two classes in June 2020. Thus, the purpose of this article is to address the remote teaching strategies adopted in PCSV, comparing the results of the first half of the discipline, developed in 2020, with those of previous years (2017, 2018 and 2019), in which only face-to-face activities were developed. The results show that, in general, the average of the first partial evaluation has improved with remote education when compared to face-toface applications.
\end{abstract}

Keywords: Remote classrooms. Face-to-face classes. Civil Engineering. 